\title{
Compostos bioativos e produção de biodiesel via saponificação direta da microalga Scenedesmus quadricauda (Turpin) Brébisson, 1835 (Chlorophyta: Scenedesmaceae)
}

Elizandra Ribeiro de Lima Pereira', Clediana Dantas Calixto $^{1}$, Marcos Barros de Medeiros ${ }^{2}$, Vilma Barbosa da

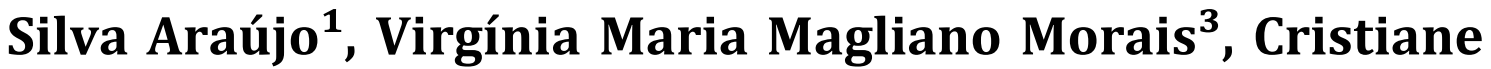
Francisca da Costa Sassi ${ }^{1}$, Hélder Formiga Fernandes4, Roberto Sassi $^{1}$ e Petrônio Filgueira de Athayde-Filho ${ }^{5}$

\footnotetext{
${ }^{1}$ Universidade Federal da Paraíba. Centro de Ciências Exatas e da Natureza. Laboratório de Ambientes Recifais e Biotecnologia com Microalgas (LARBIM). Campus I. João Pessoa-PB, Brasil (CEP 58051-900). E-mail: elizandraribeiro00@gmail.com.

${ }^{2}$ Universidade Federal da Paraíba. Centro de Educação. Departamento de Fundamentação da Educação. Campus I. João Pessoa-PB, Brasil (CEP 58051-900).

${ }^{3}$ Universidade Federal da Paraíba. Centro de Educação. Departamento de Fundamentação da Educação. Campus I. João Pessoa-PB, Brasil (CEP 58051-900).

${ }^{4}$ Universidade Federal da Paraíba. Centro de Ciências Exatas e da Natureza. Programa de Pós-Graduação em Desenvolvimento e Meio Ambiente. Campus I. João Pessoa-PB, Brasil (CEP 58051-900).

5Universidade Federal da Paraíba. Centro de Ciências Exatas e da Natureza. Laboratório de Pesquisa em Bioenergia e Síntese Orgânica (LPBS). Campus I. João Pessoa-PB, Brasil (CEP 58051-900).
}

Resumo. O uso da biomassa de microalgas na produção de biocombustíveis e extração de compostos bioativos é uma área de pesquisa que tem recebido muita atenção nos últimos anos. Objetivou-se com esse estudo realizar a extração do óleo e produção de biodiesel via saponificação direta a partir da microalga Scenedesmus quadricauda (Turpin) Brébisson, 1835 (Chlorophyta: Scenedesmaceae) e posterior identificação dos compostos bioativos presentes na fração insaponificável do processo. 0 cultivo de $S$. quadricauda foi realizado num raceway $(13.000 \mathrm{~L})$ usando extrato de biocomposto hortifrutis enriquecido com nitrato e fosfato como meio de cultura. Foram utilizados dois métodos para extração dos ésteres metílicos de ácidos graxos (saponificação e transesterificação). Os ácidos graxos foram extraídos utilizando hexano. 0 material proveniente da esterificação dos ácidos graxos obtidos via saponificação e hidrólise foi submetido a etapas de lavagem com água destilada para remoção de resquícios de solvente e catalisador. A amostra resultante foi rotaevaporada e o biodiesel obtido. Análises foram

Recebido $26 / 12 / 2019$

Aceito

$20 / 08 / 2020$

Disponível on line $27 / 08 / 2020$

Publicado $31 / 08 / 2020$

Acesso aberto

ISSN 2359-1412/RBGAS-2019-0109/2020/7/16/32/971

Rev. Bras. Gest. Amb. Sustent.

http://revista.ecogestaobrasil.net 
realizadas na fração insaponificável identificando a presença de compostos bioativos (carotenoides) em grande quantidade $(4.050 \mu \mathrm{g} / \mathrm{g})$ como rota biotecnológica de aproveitamento de biomassa residual do processo de extração e produção do biodiesel. A fração insaponificável obtida no presente estudo apresentou alto índice de antioxidantes sendo eficiente na constituição de aditivos em biodiesel na adição de 1,25\% ampliando a capacidade oxidativa do biocombustível. 0 biodiesel obtido via saponificação não apresenta viabilidade para sua utilização puro em motores devido a sua alta viscosidade e índice de oxidação pouco estabilizado, no entanto, apresenta viabilidade para sua inserção em blendas de biocombustível.

Palavras-chave: Fonte renovável; Bioenergia; Biomassa; Microalgas.

\section{Abstract. Bioactive compounds and biodiesel production via direct saponification of microalga Scenedesmus quadricauda (Turpin) Brébisson, 1835 (Chlorophyta: Scenedesmaceae). The} use of microalgae biomass in the production of biofuels and extraction of bioactive compounds is an area of research that has received much attention in recent years. The objective this study was to perform oil extraction and biodiesel production via direct saponification from microalgae Scenedesmus quadricauda (Turpin) Brébisson, 1835 (Chlorophyta: Scenedesmaceae) and later identification of bioactive compounds present in the unsaponifiable fraction of the process. The cultivation of S. quadricauda was carried out in a raceway $(13,000 \mathrm{~L})$ using extract of horticultural biocomposite enriched with nitrate and phosphate as culture medium. Two methods were used to extract the fatty acid methyl esters (saponification and transesterification). Fatty acids were extracted using hexane. The material from the esterification of fatty acids obtained via saponification and hydrolysis was subjected to washing steps with distilled water to remove traces of solvent and catalyst. The resulting sample was rotated and the biodiesel obtained. Analyzes were carried out on the unsaponifiable fraction identifying the presence of bioactive compounds (carotenoids) in large quantities $(4.050 \mu \mathrm{g} / \mathrm{g})$ as a biotechnological route for the use of residual biomass from the biodiesel extraction and production process. The unsaponifiable fraction obtained in the present study showed a high index of antioxidants, being efficient in the constitution of additives in biodiesel in the addition of $1.25 \%$, increasing the oxidative capacity of the biofuel. The biodiesel obtained via saponification is not viable for its pure use in engines due to its high viscosity and poorly stabilized oxidation index, however, it is viable for its insertion in biofuel blends.

Keywords: Renewable source; Bioenergy; Biomass; Microalgae.

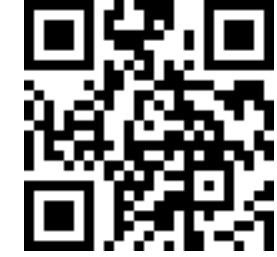

ORCID

(C) $0000-0003-3191-182 \mathrm{X}$ Elizandra Ribeiro de Lima Pereira

D 0000-0002-0812-2913

Clediana Dantas

Calixto

(D) 0000-0002-1633-3227

Marcos Barros de

Medeiros

D) 0000-0001-9973-4060

Vilma Barbosa da Silva

Araújo

D) $0000-0001-8083-1979$

Virgínia Maria

Magliano Morais

(1) $0000-0002-4980-1779$

Cristiane Francisca da

Costa Sassi

(D) 0000-0002-0370-0673

Hélder Formiga

Fernandes

(ㄷ) 0000-0001-9586-5872

Roberto Sassi

(1) 0000-0003-0982-8261

Petrônio Filgueira de

Athayde-Filho 


\section{Introdução}

A espécie Scenedesmus quadricauda (Turpin) Brébisson, 1835 (Chlorophyta: Scenedesmaceae) possui características desejáveis dentre as microalgas cultiváveis, incluindo ampla faixa de crescimento e alta produção de lipídios de em diferentes formas de cultivo em comparação com outras microalgas (Sulochana e Arumugam, 2016). Apesar de ser uma das menos exploradas, a espécie $S$. quadricauda mostrou ser a mais eficiente para a produção de biomassa e lipídios sob condições de crescimento autotrófico e mixotrófico quando comparada a outras espécies de Scenedesmus (S. obliquus, S. dimorphus, S. abundans) (Chitralekha et al., 2018).

Microalgas são microrganismos autotróficos que utilizam energia luminosa e nutrientes inorgânicos (dióxido de carbono, nitrogênio, fósforo, etc.) para desenvolver e sintetizar biocompostos que possuem alto valor agregado e funções terapêuticas, como lipídios, proteínas, carboidratos, pigmentos e polímeros. Estudos recentes relataram que as microalgas podem produzir diferentes compostos químicos com diferentes atividades biológicas, como carotenoides, ficobilinas, ácidos graxos poliinsaturados, proteínas, polissacarídeos, vitaminas e esteróis, entre outros produtos químicos (Markou e Nerantzis, 2013).

As microalgas são uma fonte natural de compostos biologicamente ativos altamente interessantes. Esses compostos têm recebido muita atenção de pesquisadores e empresas nos últimos anos devido às suas possíveis aplicações em diferentes campos. Essas aplicações vão desde a produção de biomassa para alimentos e rações até a produção de compostos bioativos para as indústrias médica e farmacêutica (Harun, 2010).

Apenas um pequeno número dentre as milhares de espécies de microalgas que se acredita existirem, é retido em coleções em todo o mundo, e estima-se que apenas algumas centenas sejam investigadas para compostos presentes em sua biomassa. Destes, apenas algumas são industrialmente cultivadas (Harun, 2010). Toda essa diversidade ainda não explorada resulta em aplicações potenciais para esses microrganismos em vários campos biotecnológicos, como a produção de biocompostos usados em alimentos, medicamentos, cosméticos e produtos farmacêuticos e no setor de energia (Kolympiris, 2014).

Considerando a enorme biodiversidade de microalgas e desenvolvimentos recentes em engenharia genética, este grupo de microrganismos é uma das fontes mais promissoras para novos produtos e aplicações (Ibañez, 2013), entre estes, o biodiesel.

A produção de biocombustível de microalgas tem várias vantagens, como a utilização de matérias-primas não alimentares, utilização de terras não aráveis para o seu cultivo e pode potencialmente utilizar uma grande variedade de recursos hídricos, incluindo águas residuais e água do mar (Rawat et al., 2013). No entanto, perpassa um grande obstáculo para este processo que é alcançar a quantidade desejada de biomassa e conteúdo lipídico simultaneamente. A maioria dos estudos realizados visando produzir mais lipídios têm cultivado microalgas em condições de estresse, incluindo a deprivação de nutrientes, porém nessas condições usualmente há redução da taxa de crescimento, afetando, consequentemente, a produtividade de biomassa.

A identificação de cepas superprodutivas é uma solução potencial que, concomitantemente com abordagens de engenharia metabólica direcionadas, pode ser aplicada para aumentar a quantidade de ácidos graxos desejáveis para melhorar a qualidade do biodiesel, superando assim a ineficiência biológica da espécie cultivada (Carreres et al., 2017). No entanto, o desenvolvimento de estirpes recombinantes que aumentam a produção de biocombustível é escasso, devido à falta de conhecimento adequado do seu genoma e às limitadas ferramentas de manipulação molecular (Vieler et al., 2012).

Neste contexto, objetivou-se, com esse estudo, analisar a composição das frações saponificáveis e insaponificáveis da microalga Scenedesmus quadricauda, obtidas após o

Rev. Bras. Gest. Amb. Sustent., 2020, vol. 7, n. 16, p. 971-994. 
processo de saponificação, e identificar os compostos bioativos presentes com possíveis aplicabilidades para processamentos biotecnológicos.

\section{Metodologia}

\section{Obtenção da biomassa}

A espécie Scenedesmus quadricauda (cepa D125WC), foi selecionada para realização deste estudo o qual foi desenvolvido no Laboratório de Ambientes Recifais e Biotecnologia com Microalgas, Campus I (LARBIM/UFPB) e no Núcleo de Pesquisa e Processamento de Alimentos CT/CTDR/UFPB. A espécie cultivada (Scenedesmus quadricauda) foi selecionada com base em estudos prévios, por apresentar perfil dentro dos parâmetros adequados para produção de biodiesel, melhor produtividade e por sua capacidade de decantar quando na fase estacionária, facilitando dessa forma a colheita de sua biomassa. 0 cultivo foi realizado em tanque aberto (raceway) com capacidade de $13.000 \mathrm{~L}$ de água. Utilizou-se um extrato de biocomposto hortifrutis (BH) preparado a partir da compostagem de restos de legumes e verduras descartados durante a comercialização pela Empresa Paraibana de Abastecimento e Serviços Agrícolas (EMPASA), localizada no município de João Pessoa, para cultivo da espécie. A preparação deste meio deu-se de acordo com o procedimento descrito por Erd-Schreiber modificado (Gross, 1937), onde a $1 \mathrm{~kg}$ do biocomposto foi adicionado $1 \mathrm{~L}$ de água de poço, seguido de aquecimento por $30 \mathrm{~min}$, com posterior filtração, sendo os extratos mantidos sob refrigeração $\left(2-8{ }^{\circ} \mathrm{C}\right)$ até sua utilização. Para a preparação deste meio realizou-se a adição em água de poço do extrato na concentração de $10 \mathrm{~mL} \cdot \mathrm{L}^{-1}$ e de soluções de nitrato e fosfato nas proporções de $1 \mathrm{~mL} . \mathrm{L}^{-1}$, seguido do ajuste do $\mathrm{pH}$ para neutralidade (Gross, 1937). 0 desenvolvimento dos cultivos foi acompanhado através de medidas da fluorescência in vivo usando um fluorímetro Turner Design 10005R para a determinação da curva de crescimento. A colheita foi realizada na fase estacionária e a biomassa colhida foi seca em estufa de circulação forçada a $45^{\circ} \mathrm{C}$, posteriormente pesada e armazenada para análises.

\section{Análise da microalga Scenedesmus quadricauda seca e suas diferentes frações e produtos}

A metodologia utilizada para análise de algas secas e suas diferentes frações e produtos foi adaptada de Viegas et al. (2015) (Figura 1).

A biomassa seca da microalga ( $250 \mathrm{~g}$ ) inicialmente foi submetida a um processo de saponificação, onde foi utilizado $800 \mathrm{~mL}$ de uma solução etanólica de $\mathrm{KOH}$ a $5 \%$. A saponificação foi realizada a $70{ }^{\circ} \mathrm{C}$, sob agitação, durante $1 \mathrm{~h}$. Em seguida, o material foi filtrado a vácuo para separação da biomassa sólida, com a disposição da fração líquida em um funil de decantação. $200 \mathrm{~mL}$ de uma mistura hexano: água, na proporção 70:30 (v/v), foi adicionada a fração líquida, com posterior agitação. A mistura foi mantida em repouso até uma completa separação das fases, na qual foram obtidas uma fração apolar - fase superior - rica em material insaponificável e uma fração polar - inferior - composta de material saponificável (ácidos graxos). 0 processo de extração das frações a partir da lavagem com a mistura hexano:água foi repetido quatro vezes.

A fração apolar foi lavada sucessivamente com água destilada até obtenção de $\mathrm{pH}$ neutro. 0 solvente foi removido da amostra por rotaevaporação a $35{ }^{\circ} \mathrm{C}$ e o extrato insaponificável obtido foi acondicionado sob abrigo da luz.

A fração polar foi submetida a um processo de hidrólise com adição de uma quantidade molar estequiométrica de $\mathrm{H}_{2} \mathrm{SO}_{4}$ até uma faixa de $\mathrm{pH}$ entre 1 e 2 . A hidrólise foi realizada sob agitação magnética a $80^{\circ} \mathrm{C}$, durante $60 \mathrm{~min}$. Em seguida, a amostra foi transferida para um funil de separação e os ácidos graxos foram obtidos através de sucessivas extrações com hexano $(4 \times 100 \mathrm{~mL})$. 0 hexano foi recuperado em 
rotaevaporador e os ácidos graxos obtidos foram pesados gravimetricamente e submetidos ao processo de transesterificação.

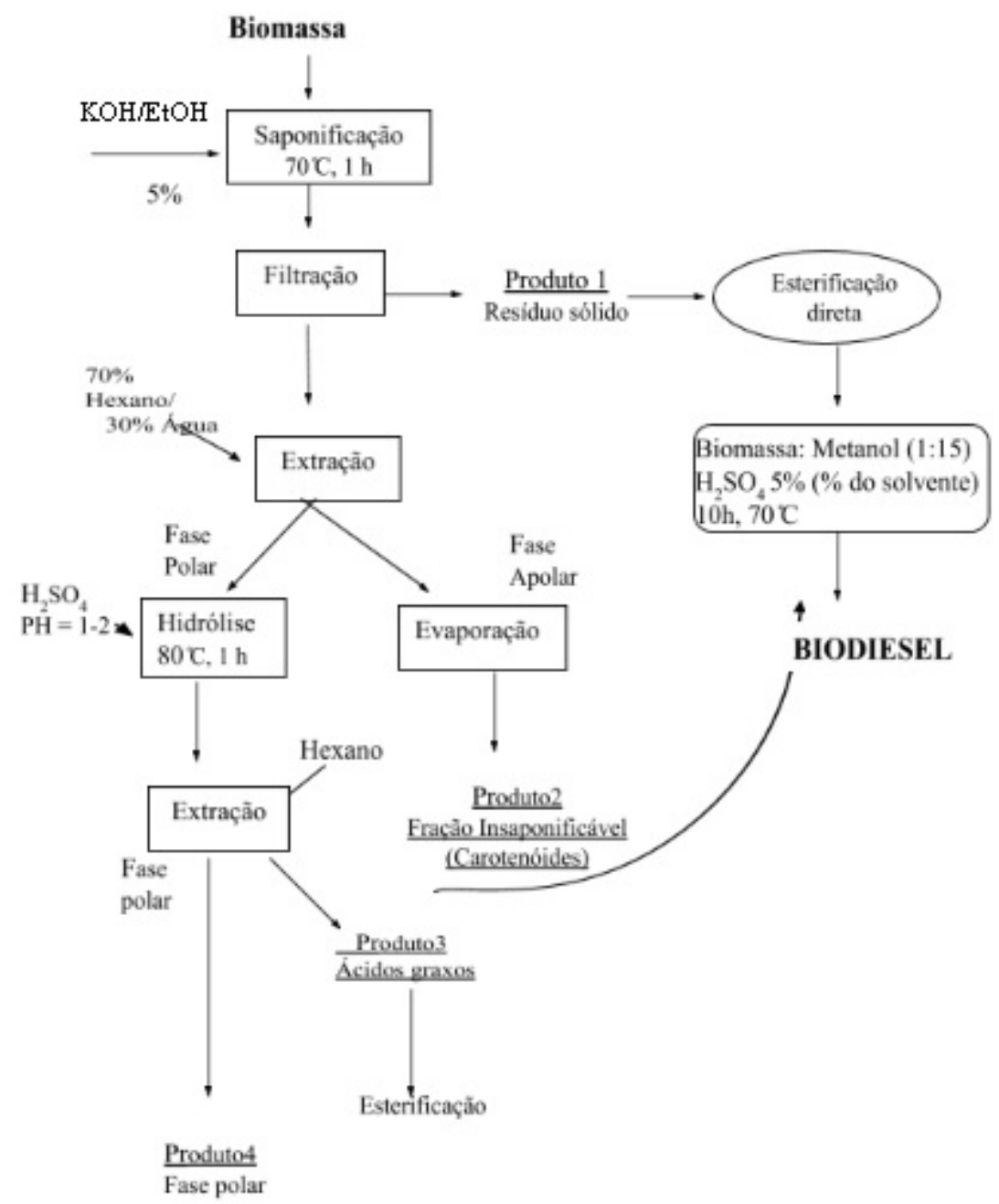

Figura 1. Fluxograma das etapas do processo produtivo do biodiesel.

A transesterificação tanto dos ácidos graxos provenientes da fração polar quanto do resíduo sólido (Produto 1), separado após o processo de saponificação, foi realizado por meio de catálise ácida com a utilização de $\mathrm{H}_{2} \mathrm{SO}_{4}$ a $5 \%$ em metanol na proporção biomassa/ácidos graxos: metanol - 1:15 (m/v). A transesterificação foi conduzida sob agitação por $6 \mathrm{~h}$ com aquecimento controlado a $60^{\circ} \mathrm{C}$.

0 produto obtido da transesterificação direta da biomassa foi submetido a sucessivas lavagens com hexano: água para separação da fração contendo os ésteres de ácidos graxos. Seguidamente o biodiesel foi obtido através da remoção do solvente, da fase apolar, em rotaevaporador a $40^{\circ} \mathrm{C}$.

0 material proveniente da transesterificação dos ácidos graxos obtidos via saponificação e hidrólise foi submetido a etapas de lavagem com água destilada para remoção de resquícios de solvente e catalisador. A amostra resultante foi rotaevaporada e o biodiesel obtido. 


\section{Caracterização do óleo de microalgas (fração saponificável)}

Índice de acidez. A determinação do índice de acidez foi realizada como sugere o método NBR 11115 (AOCS, 2009).

Perfil de ácidos graxos. Realizou-se uma esterificação metílica seguindo metodologia descrita por Hartman e Lago (1973) para a determinação do perfil de ácidos graxos da biomassa, e a quantificação foi obtida por curva de calibração com padrões de ésteres metílicos, utilizando um GCMS-QP2010 (Shimadzu, Kyoto, Japan) equipado com uma coluna Durabond (DB-23 $30 \mathrm{~m} \times 0,25 \mathrm{~mm} \times 740,25 \mu \mathrm{m}$ ). A temperatura do injetor e do detector foram fixados em $230{ }^{\circ} \mathrm{C}$ e temperatura da coluna em $90{ }^{\circ} \mathrm{C}$. 0 gradiente de eluição na coluna foi de 90 a $150{ }^{\circ} \mathrm{C}\left(10^{\circ} \mathrm{C} / \mathrm{min}\right), 150$ a $200{ }^{\circ} \mathrm{C}\left(5^{\circ} \mathrm{C} / \mathrm{min}\right), 200$ a $230{ }^{\circ} \mathrm{C}$ $\left(3^{\circ} \mathrm{C} / \mathrm{min}\right)$ em um tempo total de corrida de $34 \mathrm{~min}$, utilizando como gás de arraste o hélio na vazão de $1 \mathrm{~mL} / \mathrm{min}$.

Análise de infravermelho. Os espectros de absorção na região do infravermelho foram obtidos em Espectrofotômetro marca Shimadzu, modelo IR Prestige, utilizando o suporte de amostra: ATR de mono reflexão com cristal de ZnSe na faixa de 4.000-650 $\mathrm{cm}^{-1}$.

Termogravimetria. As curvas termogravimétricas (TG) foram obtidas em Analisador Térmico Shimadzu, massa de $10 \mathrm{mg}$, cadinho de alumina, razão de aquecimento de $10{ }^{\circ} \mathrm{C} / \mathrm{min}$., em atmosfera de nitrogênio, fluxo de $50 \mathrm{~mL}$ de temperatura ambiente até $700^{\circ} \mathrm{C}$.

Viscosidade. A viscosidade cinemática do biodiesel obtido foi realizada pelo método ABNT NBR 10441 (ABNT, 2014), utilizando um viscosímetro cinemático manual (modelo ME18V da Julabo). Durante o procedimento realiza-se a medição do tempo requerido para que o volume de $10 \mathrm{~mL}$ do biodiesel escoe sob gravidade, através do tubo viscosímetro.

O tubo de especificação W0927 permanece imerso durante a determinação em um banho viscosímetro a $40{ }^{\circ} \mathrm{C}$. A partir da constante $k$ do tubo e do tempo medido experimentalmente, a viscosidade cinemática pode então ser calculada utilizando a equação 1:

$$
\mathbf{v}=\mathbf{k}+\mathbf{t}
$$

Onde: $\mathrm{v}=$ viscosidade cinemática $\left(\mathrm{mm}^{2} \mathrm{~s}^{-1}\right) ; \mathrm{k}=$ constante de capilaridade do viscosímetro $\left(0,007931 \mathrm{~mm}^{2} / \mathrm{s}^{2}\right) ; \mathrm{t}=$ tempo $(\mathrm{s})$.

\section{Avaliação da estabilidade oxidativa do biodiesel}

Rancimat. Os ensaios da estabilidade oxidativa foram realizados em triplicata utilizando o equipamento Rancimat da marca Metrohm modelo 743 (Metrohm, Herisau, Suíça). Segundo metodologia EN14112 (2003) é um teste acelerado e expressa o resultado em período de indução (PI), definido como o intervalo de tempo correspondente ao ponto de inflexão da curva de condutividade versus tempo. Determinou-se a análise a $110{ }^{\circ} \mathrm{C} \mathrm{e}$ $10 \mathrm{~L}$ de ar/h, utilizando $3 \mathrm{~g}$ de amostra em cada tubo de reação.

Calorimetria Exploratória diferencial (DSC). As curvas DSC foram obtidas através de um calorímetro diferencial de varredura acoplado a uma célula de pressão DSC-60 Phoenix NETZSCH sob atmosferas dinâmicas de nitrogênio, pressão atmosférica, temperatura de $50{ }^{\circ} \mathrm{C}$ a $550{ }^{\circ} \mathrm{C}$ com uma razão de aquecimento de $10{ }^{\circ} \mathrm{C} / \mathrm{min}$ e fluxo de gás de $50 \mathrm{~mL} / \mathrm{min}$. 0 cadinho utilizado foi de alumina. 


\section{Caracterização da fração insaponificável}

Determinação da atividade antioxidante pelo poder redutor do ferro (FRAP). A capacidade antioxidante dos extratos de microalgas foi realizada em triplicata e ao abrigo da luz, seguindo a metodologia de Rufino et al. (2006). 0 ensaio do FRAP ou poder antioxidante em reduzir o ferro é baseado na capacidade de um antioxidante reduzir o $\mathrm{Fe}^{3+}$ para $\mathrm{Fe}^{2+}$. A solução do reagente FRAP foi preparada com $25 \mathrm{~mL}$ de tampão acetato 0,3 M, uma alíquota de 2,5 mL da solução TPTZ (2,4,6-Tris(2-piridil)-s-triazina) a $10 \mathrm{mM}$ e $2,5 \mathrm{~mL}$ de solução aquosa de cloreto férrico $20 \mathrm{mM}$. Adicionou-se $90 \mu \mathrm{L}$ de cada extrato em tubos, $270 \mu \mathrm{L}$ de água destilada, seguido de $2,7 \mathrm{~mL}$ do reagente FRAP. Após homogeneização, os tubos foram mantidos em banho-maria a $37{ }^{\circ} \mathrm{C}$. Calibrou-se $\mathrm{o}$ espectrofotômetro UV-VIS (Thermo Fisher Scientific, modelo Evolution 60S) com o reagente FRAP e as leituras da absorbância realizadas após 30 min da mistura, a $595 \mathrm{~nm}$. A curva padrão foi preparada utilizando Trolox (6-hidroxi-2,5,7,8-tetramethylchroman-2-

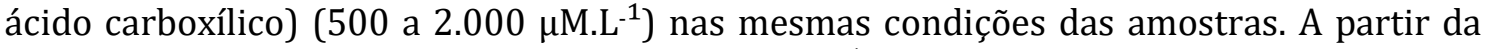
equação da reta do gráfico concentração $\left(\mathrm{mg}_{\mathrm{L}} \mathrm{L}^{-1}\right)$ versus absorbância (nm), pode-se calcular a capacidade antioxidante total. Os resultados da capacidade antioxidante foram expressos em $\mu \mathrm{M}$ Trolox. $\mathrm{g}^{-1}$ extrato (capacidade antioxidante equivalente ao Trolox).

Atividade sequestradora do radical (2,2-diphenyl-1-picrylhydrazyl - DPPH). A atividade antioxidante foi determinada através da capacidade dos antioxidantes presentes nas amostras em sequestrar o radical estável DPPH de acordo com a metodologia descrita por Brand-Willams et al. (1995). A partir de triagem preliminar, alíquotas de $90 \mu \mathrm{L}$ dos extratos foram misturadas com $210 \mu \mathrm{L}$ de etanol e $2.700 \mu \mathrm{L}$ da solução de DPPH, em triplicata. As leituras foram realizadas após 30 minutos a $517 \mathrm{~nm}$, em espectrofotômetro UV-vis (Thermo Fisher Scientific, modelo Evolution 60S). Uma curva padrão foi preparada utilizando Trolox em concentrações de 0,5 a $5 \mu \mathrm{g} \cdot \mathrm{mL}^{-1}$. Os resultados da capacidade antioxidante foram expressos em $\mu \mathrm{M}$ Trolox. ${ }^{-1}$ extrato (capacidade antioxidante equivalente ao Trolox).

Determinação dos compostos fenólicos. Os fenólicos extraíveis totais das microalgas foram determinados de acordo com o método colorimétrico de FolinCiocalteau (Slinkard e Singleton, 1977). Preparou-se a mistura de $60 \mu \mathrm{L}$ do reagente de Folin-Ciocalteau, após 1 min de agitação seguindo-se com a $2.520 \mu \mathrm{L}$ de água destilada e $180 \mu \mathrm{L}$ de carbonato de sódio a 15\%. Essa mistura foi agitada e mantida no escuro por $2 \mathrm{~h}$. A absorbância foi medida em espectrofotômetro UV-vis (Thermo Fisher Scientific, modelo Evolution 60S) a $760 \mathrm{~nm}$, juntamente com o controle que continha somente água e os reagentes. A concentração de compostos fenólicos foi estimada usando curva de calibração de ácido gálico (2-200 mg.mL $\left.\mathrm{m}^{-1}\right)$, sendo os resultados expressos como média \pm desvio-padrão de mg equivalente de ácido gálico (GAE) em cada grama de extrato.

Identificação de pigmentos. Para a análise de pigmentos utilizou-se um espectrofotômetro (Thermo Spectronic - GENESYS 10uv) a $450 \mathrm{~nm}$. Utilizou-se amostras da fração saponificável $(0,3309 \mathrm{~g})$ e insaponificável $(0,3146 \mathrm{~g})$ diluído em $3 \mathrm{~mL}$ de clorofórmio P.A, os quais foram totalmente transferidos para uma cubeta de vidro para então serem lidos no espectrofotômetro. A absorbância obtida foi convertida em concentração de carotenoides totais por meio da relação de Beer-Lambert, a qual está descrita na Equação a seguir (Kanzy et al., 2015; Cheng e Yang, 2016):

$$
[\text { Carotenoides }]_{\text {totais }}=\frac{\text { A.V. } 10^{4}}{\text { a.m }}
$$


Onde:

[Carotenoides] totais: Concentração de Carotenoides totais em $\mu \mathrm{g} / \mathrm{g}$ de células;

A: absorbância a $450 \mathrm{~nm}$;

V: volume de solvente no qual a amostra foi diluída ( $3 \mathrm{~mL})$;

a: absortividade molar da espécie química (carotenoides em geral, 2592);

m: massa da amostra da qual os compostos foram extraídos (g).

Cromatografia de Camada Delgada (CCD). As análises cromatográficas foram realizadas em temperatura ambiente de $20{ }^{\circ} \mathrm{C} \pm 22{ }^{\circ} \mathrm{C}$ executada sobre placa de acrílico, revestida com uma fina camada de material adsorvente, sílica-gel; na placa, com o auxílio de capilares, foram aplicadas amostras de licopeno e betacaroteno. Nas câmaras de elição utilizadas foi adicionado um papel de filtro, e solventes diferentes, sendo eles hexano/acetato de etila (1:1).

As placas foram então colocadas nas câmaras de eluição, durante 5 minutos para que houvesse uma boa adsorção. Em seguida as placas foram conduzidas à capela, para que se desse a evaporação dos solventes para poderem ir então para as câmaras de revelação, por cerca de 5 a 8 min, onde continham cristais de iodo. Os diferentes componentes percorreram a placa de CCD de maneira diferentes, sendo possível a separação dos componentes e análise da distância percorrida.

\section{Análise estatística}

Todos os dados obtidos para cada análise efetuada foram submetidos a tratamento estatístico utilizando o programa Sisvar para média e desvio padrão.

\section{Resultados e discussão}

\section{Rendimento em biomassa, perfil de ésteres e atividade antioxidante}

A espécie Scenedesmus quadricauda apresentou taxa de crescimento muito rápida no meio de cultura alternativo utilizado (biocomposto hortifruti), alcançando a fase estacionária em apenas 10 dias. 0 rendimento da biomassa cultivada foi de 0,392 g.L-1.

A análise da composição em ácidos graxos da biomassa de Scenedesmus quadricauda (Tabela 1) apresentou em sua composição $51,26 \%$ de ácidos graxos saturados, 27,08\% monoinsaturados e $21,66 \%$ poliinsaturados. Sulochana e Arumugam (2016) relataram 66,59\% de ácidos graxos saturados, 28,62\% monoinsaturados e 4,78\% poliinsaturados também em Scenedesmus quadricauda.

Os ácidos graxos com maiores expressões foram palmítico (39,12\%), oleico $(15,85 \%)$ e o $\alpha$-linolênico $(11,77 \%)$. Bermudez-Sierra (2018) em seu trabalho sobre extração de lipídeos com diferentes solventes orgânicos, encontrou uma maior frequência no perfil de ácidos graxos de todos os tratamentos submetidos à Scenedesmus sp. para o ácido ácido oleico (C18:1n9c) e ácido linoleico (C18:2n6c).

0 biodiesel obtido pela rota da saponificação direta da biomassa microalgal apresentou índice de insaturação um pouco mais elevado. 0 que demonstra a ineficiência do processo para obtenção de um biodiesel de qualidade, porém, bastante eficiente no tocante à extração de compostos bioativos, como carotenoides que são de grande importância para indústria alimentar e farmacêutica. Viegas et al. (2015) avaliaram a eficiência da extração de carotenoides via saponificação direta e concluíram que o processo torna-se efetivo com o uso da solução etanólica $\mathrm{KOH}$ a $5 \%$ e a $10 \%$ devido à eficiência do etanol em separar os carotenos, que são muito hidrofóbicos e não contêm grupos hidroxila. Dessa forma, os resultados são promissores mostrando que, usando o biocompatível etanol/KOH no pré-tratamento da microalga seguido da extração com hexano, o rendimento de carotenoides não diminuiu em comparação com a extração com outros métodos citados na literatura. 
Tabela 1. Composição em ácidos graxos do biodiesel obtido por saponificação da microalga Scenedesmus quadricauda.

\begin{tabular}{|l|c|}
\hline Ácidos graxos (\%) & Biodiesel \\
\hline C12:0 ácido láurico & 0 \\
\hline C13:0 ácido tridećlico & 0 \\
\hline C14:0 ácido mirístico & 0,64 \\
\hline C14:1 ácido miristoleico & 0 \\
\hline C15:0 ácido pentadecílico & 0,95 \\
\hline C16:0 ácido palmítico & 24,12 \\
\hline C16:1 ácido palmitoleico & 3,42 \\
\hline C17:1 ácido Heptadecenóico & 0,33 \\
\hline C18:0 ácido esteárico & 4,03 \\
\hline C18:1n9t ácido elaídico & 3,17 \\
\hline C18:1n9c ácido oléico & 20,40 \\
\hline C18:2n6c ácido linoleico & 34,35 \\
\hline C18:3n6 ácido $\gamma$ - linoléico & 0,0 \\
\hline C18:3n3 ácido $\alpha$-linolênico & 6,11 \\
\hline C20:0 ácido araquídico & 0,28 \\
\hline C20:5n3c ácido & 0,00 \\
\hline C22:0 ácido behênico & 0,00 \\
\hline AGS & 30,78 \\
\hline AGMI & 27,32 \\
\hline AGPI & 40,46 \\
\hline
\end{tabular}

\section{Saponificação direta da biomassa microalgal}

A saponificação direta da biomassa microalgal foi realizada com a presença do agente alcalino KOH. 0 processo de extração de saponificação direta (Fig. 1) foi realizado em uma solução etanólica KOH a 5\%, uma vez que ambas as frações, saponificáveis (ácidos graxos) e insaponificáveis já foram eficientemente extraídos sob essas condições. Como resultado do processo, foram obtidos quatro produtos diferentes.

A fração obtida do produto 1 foi de $85,2 \%$, enquanto as frações do produto 2 , ricas em carotenoides, e produto 3 contendo ácidos graxos foram de 3,2\% e 6\%, respectivamente, totalizando $94,4 \%$ em peso. Este valor indica que $6,4 \%$ em peso de biomassa compõe a fração polar contendo proteínas e outros compostos como produto 4.

Várias análises foram realizadas com o produto 1 tratado com a solução etanólica $\mathrm{KOH}$ a $5 \%$. 0 resultado mostrando que a massa do produto 1 era de $84 \%-85 \%$ em peso da biomassa inicial, é bastante relevante, indicando assim que a concentração de álcali exibia apenas um efeito menor na massa do produto 1 . Cerca de $50 \%$ das proteínas acabaram no produto 4 , quando a concentração alcalina era de $1 \%$. Após a saponificação, a maioria dos elementos membranosos, incluindo tilacoides e amido são perdidos, a parede celular perde sua rigidez original, facilitando a extração dos lipídios e demais componentes presentes no interior das células.

A fração de massa do produto 2, compostos insaponificáveis, tratado com a solução etanólica $\mathrm{KOH}$ a $5 \%$ foi de $3,2 \%$ do peso da biomassa microalgal (250 g). Ao final do processo, foi obtido $15 \mathrm{~g}(19,1 \mathrm{~mL})$ de biodiesel extraído de $250 \mathrm{~g}$ de biomassa.

\section{Caracterização do óleo da microalga scenedesmus quadricauda}

A viscosidade cinemática do óleo é parâmetro de referência que ajuda na determinação do tempo de reação de transesterificação, sendo que uma viscosidade elevada aumenta o tempo da síntese. 
O biodiesel obtido pelo processo de saponificação seguido de transesterificação apresentou valores de viscosidade acima da norma estabelecida pela ANP (Brasil, 2007) que é de 3,0-6,0 (Cst), mesmo submetido à reação de transesterificação do óleo, que tem como característica principal diminuir este parâmetro. Tal valor $(16,4)$ é influenciado pelas propriedades do ácido oléico (C18:1), ácido graxo presente em grande quantidade no óleo oriundo de $S$. quadricauda (Tabela 1) que promove as interações intermoleculares como Forças Van der Walls que devido a molécula possuir uma grande massa molecular se acentuam expressivamente, ocasionando o aumento do tempo de escoamento do biodiesel. Devido a isso os valores encontrados para a viscosidade do biodiesel, por ser alto impõe cuidados e restrições ao uso direto do biodiesel obtido por esta rota, podendo ser usado em misturas nos motores ciclo-diesel.

0 espectro de Infravermelho por Transformada de Fourier (FTIR) do biodiesel obtido de Scenedesmus quadricauda por saponificação direta, foi obtido no intervalo de 4.500 a $500 \mathrm{~cm}^{-1}$. Essa técnica qualitativa permite saber quais são os grupos orgânicos mais importantes referentes aos componentes do biodiesel analisado.

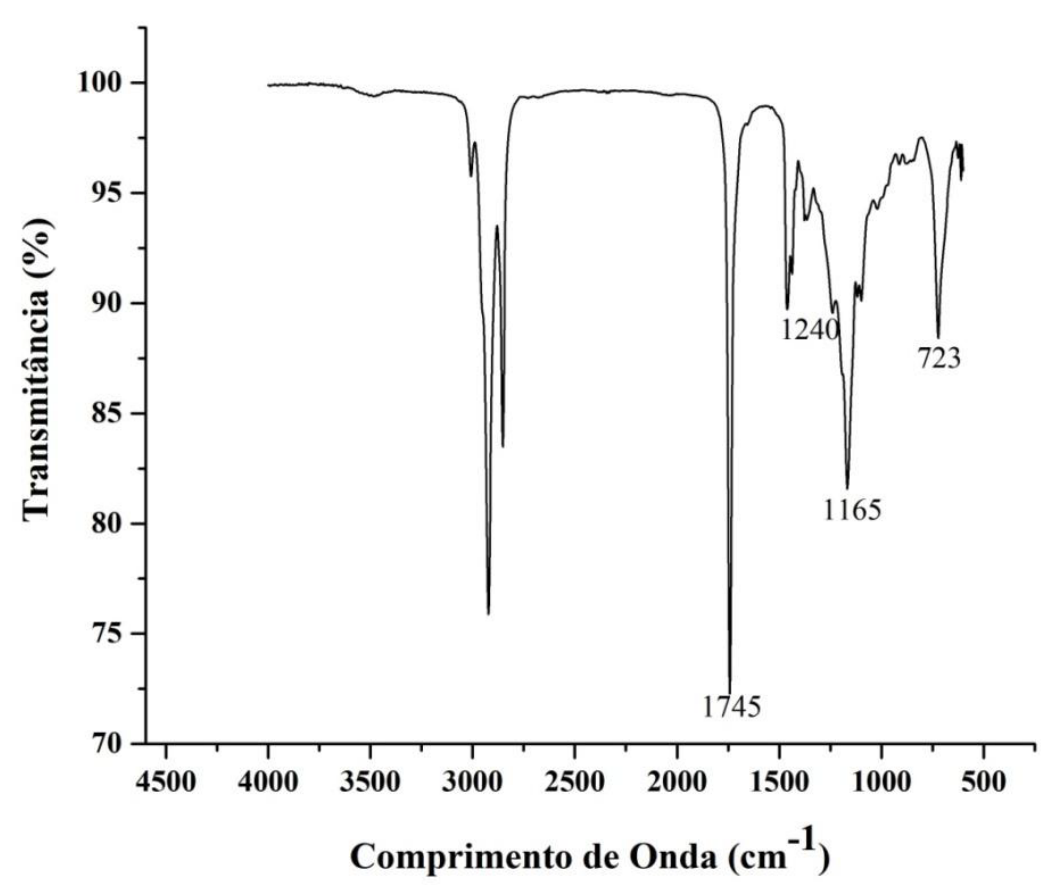

Figura 2. Espectro de Infravermelho do biodiesel obtido via saponificação direta da microalga Scenedesmus quadricauda.

O FTIR (Figura 2) apresentou absorção forte em $1.745 \mathrm{~cm}^{-1}$ referente a deformação axial do grupo éster $(C=0)$, a presença dessa banda característica da carbonila é bastante útil para diferenciar o óleo diesel do biodiesel. Duas absorções médias referentes à deformação axial do grupo C-O de éster $\left(1.165 \mathrm{~cm}^{-1}\right.$ e $\left.1.240 \mathrm{~cm}^{-1}\right)$ também foram observados.

Os grupos metilênicos $\left(\mathrm{CH}_{2}\right) \mathrm{n}$ da cadeia carbônica dos ésteres foram confirmados pelas bandas nas regiões de $3000 \mathrm{~cm}^{-1}$ e $723 \mathrm{~cm}^{-1}$, referentes aos movimentos vibracionais de deformações axiais, e de deformações angulares das ligações C-H respectivamente (Silverstein e Webster, 2007). 


\section{Análises da fração insaponificável}

Para análise antioxidante presentes na fração insaponificável, utilizou-se os testes de compostos fenólicos totais, DPPH, FRAP.

Os resultados apresentados possuíam a atividade de eliminação de DPPH em 76,74\%. Outros estudos relatados por Choochote et al. (2013) demonstraram atividade de eliminação de $68,18 \%, 58,98 \%$ e $54,89 \%$ do radical DPPH, no extrato etanólico para as espécies Chlorella sp. E53, Chlorella sp. ED53 e Chlorococcum sp. C53, respectivamente, reportando-nos a uma atividade antioxidante maior para o extrato da microalga Scenedesmus quadricauda encontrada neste estudo.

A atividade antioxidante também foi determinada com base na capacidade de reduzir o ferro férrico $\left(\mathrm{Fe}^{3+}\right)$ ao estado ferroso $\left(\mathrm{Fe}^{2+}\right)$, obtendo nesse estudo 45,83 $\mu \mathrm{mol}$ Sulfato Ferroso.g-1 o que determina uma excelente capacidade antioxidativa da microalga em estudo.

Estudos realizados por Araújo (2018) relatam valores para os extratos etanólicos para as espécies Coelastrum sp. D294WC e Monoraphidium contortum D525WC (31,85 e 27,03 $\mu$ mol Sulfato Ferroso.g-1 respectivamente).

A análise de pigmento realizado nas frações saponificável e insaponificável, apresentou valores significativos de presença de carotenoides. Para a amostra saponificável, a leitura em espectrofotômetro apresentou 54,8 $\mu \mathrm{g} / \mathrm{g}$ de carotenoides, em contrapartida com o alto valor encontrado na fração insaponificável $(4.050 \mu \mathrm{g} / \mathrm{g})$, o que ratifica o resultado presumido da amostra devido a coloração intensa do material extraído, denotando presença significativa de pigmentos.

Estudos realizados por Nogara et al. (2015), quando da quantificação de carotenoides totais da microalga Phormidium autumnale, encontraram valores de $476,25 \mu \mathrm{g} / \mathrm{g}$ em sua biomassa. Nomura et al. (2015) em seu trabalho sobre composição química e atividade biológica da microalga Chlorella sorokiniana encontraram valores de $829,5 \mu \mathrm{g} \mathrm{L}-1$.

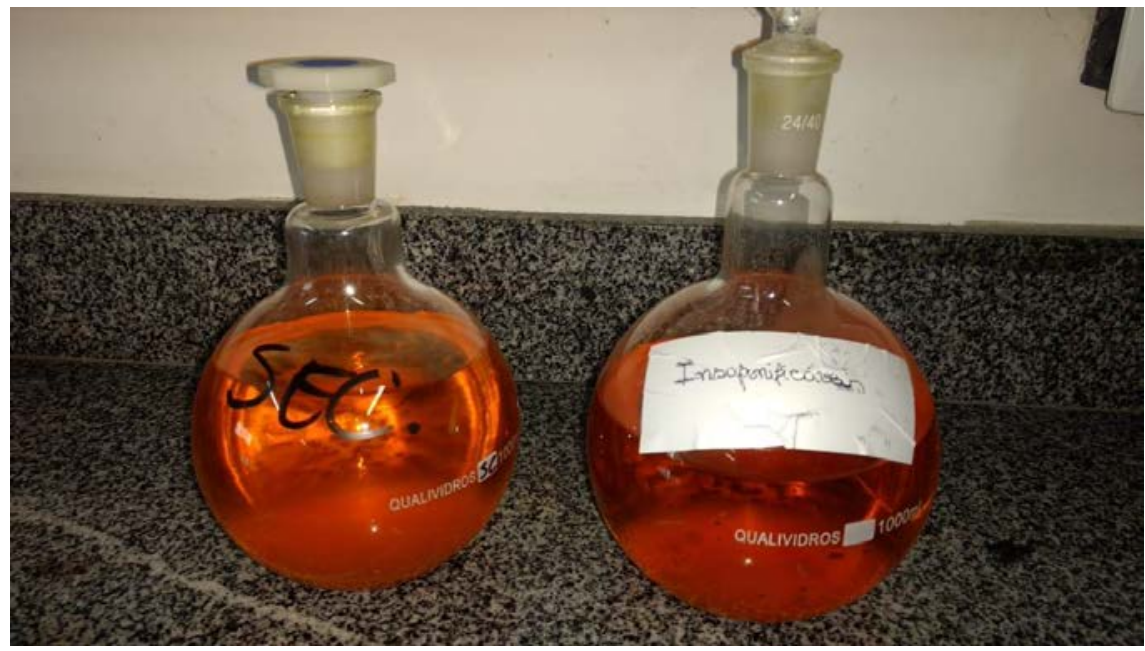

Figura 3. Fração insaponificável extraída do processo de saponificação da biomassa de S. quadricauda.

Diante dos resultados apresentados em estudos anteriores, podemos afirmar que a microalga Scenedesmus quadricauda apresenta quantidade significativa (cerca de $100 \%$ a 
mais) de Carotenoides Totais em sua composição, o que a torna uma excelente candidata à exploração biotecnológica de seus constituintes biológicos.

\section{Estudos de purificação da massa de carotenoides de Scenedesmus quadricauda}

Estudos de Cromatografia de placa tendo como eluente hexano/acetato de etila (1:1) (Figura 4), mostram que a biomassa é comprovadamente constituída por mais de uma espécie de carotenoide, entretanto parece apresentar um carotenoide majoritário com $\mathrm{rf}=0,37$, entretanto carotenoides em menores percentuais são observados acima e abaixo do composto majoritário.

$\mathrm{Na}$ tentativa inicial para purificar, ou seja, separar a mistura de carotenoides totais presentes na fração insaponificável da biomassa de $S$. quadricauda foi realizado uma cromatografia preparativa, com $0,100 \mathrm{~g}$ da mistura de carotenoides, em mesmo eluente, hexano/acetato de etila (1:1), como fase móvel. A placa de cromatografia preparativa, figura 5, mostra uma mistura mais evidenciada compreendida por carotenoides como organizado a seguir: Ficaram retidos na linha base (C1), carotenoide que foi totalmente arrastados pelo eluente na linha superior (C5), um tipo de carotenoide mais abundante de cor amarela intensa em uma posição mais intermediária (C3) e mais dois tipos de carotenoides, acima (C4) e abaixo (C2), bastante perceptíveis.

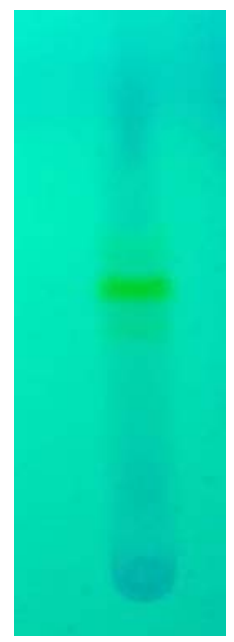

Figura 4. Cromatografia de placa comparativa da fração insaponificável da microalga Scenedesmus quadricauda.

Os carotenoides, pigmentos responsáveis pela cor alaranjada dos vegetais, compreendem grande número de compostos dos quais apresentam atividades biológicas (Costa e Rosa, 2010). 


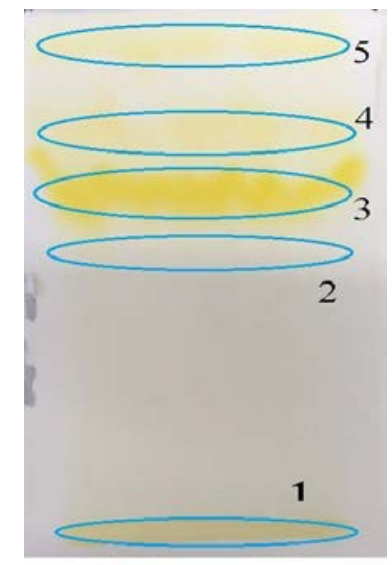

Figura 5. Cromatografia de placa comparativa da fração insaponificável da microalga Scenedesmus quadricauda.

As frações identificadas na placa preparativa foram cortadas e os carotenoides extraídos com acetato de etila, filtrados e o solvente evaporado, gerando quatro amostras de carotenoides, C1 $(<0,0001 \mathrm{~g}), \mathrm{C} 2(<0,0001 \mathrm{~g}), \mathrm{C} 3(0,0512 \mathrm{~g}), \mathrm{C} 4(0,0201 \mathrm{~g})$ e C5 $(0,0156 \mathrm{~g})$ As amostras se apresentaram com aparência oleosa, entretanto das frações C1 e C2 não foi possível fazer os estudos de infravermelho devido a quantidade ser menor que $0,0001 \mathrm{~g}$.

\section{Análise de Infravermelho da fração insaponificável (carotenoides)}

A espectroscopia de infravermelho por transformada de Fourier (FTIR) é uma ferramenta laboratorial bastante versátil e sensível, que possibilita a identificação de ligações químicas em compostos, por meio da interação do feixe de infravermelho com a energia das ligações químicas, compreendendo o espectro rotacional e vibracional (Antonino, 2016).

Estudos de FTIR mostram espectros característicos para carotenoides, tanto para o produto total insaponificável, bem como para as frações obtidas da placa preparativa, corroborando com as análises feitas para carotenoides por Ortega-Cabello et al. (2016).

Os resultados da espectroscopia na região do UV-visível ilustram bandas características de compostos carotenoides. Apesar de ainda não termos realizados testes cromatográficos para a identificação dos carotenoides presentes nas amostras de pigmentos, com base nas características espectrais pode-se inferir que a cor alaranjada do pigmento extraídos são provenientes de carotenoides. Os resultados da espectroscopia na região do Infravermelho revelam sinais espectrais característicos de compostos carotenoides e outros compostos também, como proteínas, ácidos graxos e compostos fenólicos (Babu et al. 2008).

No espectro de infravermelho da mistura de carotenoides totais, CCT (Figura 6), indica a presença da função hidroxila devido a banda de absorção em $3.367 \mathrm{~cm}^{-1}(\mathrm{vOH})$, e pode ser atribuída à degradação dos componentes da parede celular. Os carbonos $\mathrm{sp}^{2} \mathrm{e} \mathrm{sp}^{3}$ podem ser certificados na estrutura devido a existências de bandas de absorção entre 3.000-2.859 $\mathrm{cm}^{-1}$, já as bandas de média a forte intensidade ao redor de $1.709 \mathrm{~cm}^{-1}$ são características para a função de grupo carbonila nos carotenoides. As bandas em $1.668 \mathrm{~cm}^{-1}(v \mathrm{C}=\mathrm{C})$ que também ocorrem em alcenos conjugados, está sendo atribuída à presença de ligações duplas no material lipídico (Rohman e Man, 2010). As bandas de absorção em $1.462 \mathrm{~cm}^{-1}$ e $1.377 \mathrm{~cm}^{-1}$ também indicativos das vibrações de deformação angular de $\mathrm{C}-\mathrm{H} \mathrm{sp} \mathrm{sp}^{3}$ e as bandas em $1.050 \mathrm{~cm}^{-1}$ é característica de uma função tipo álcool 
primário $(v \mathrm{C}-\mathrm{OH})$ e a banda abaixo de $700 \mathrm{~cm}^{-1}$ é indicativo da vibração angular $v \mathrm{C}-\mathrm{H}$ fora do plano de carbono-hidrogênio insaturado $\left(\mathrm{Csp}^{2}\right)$.

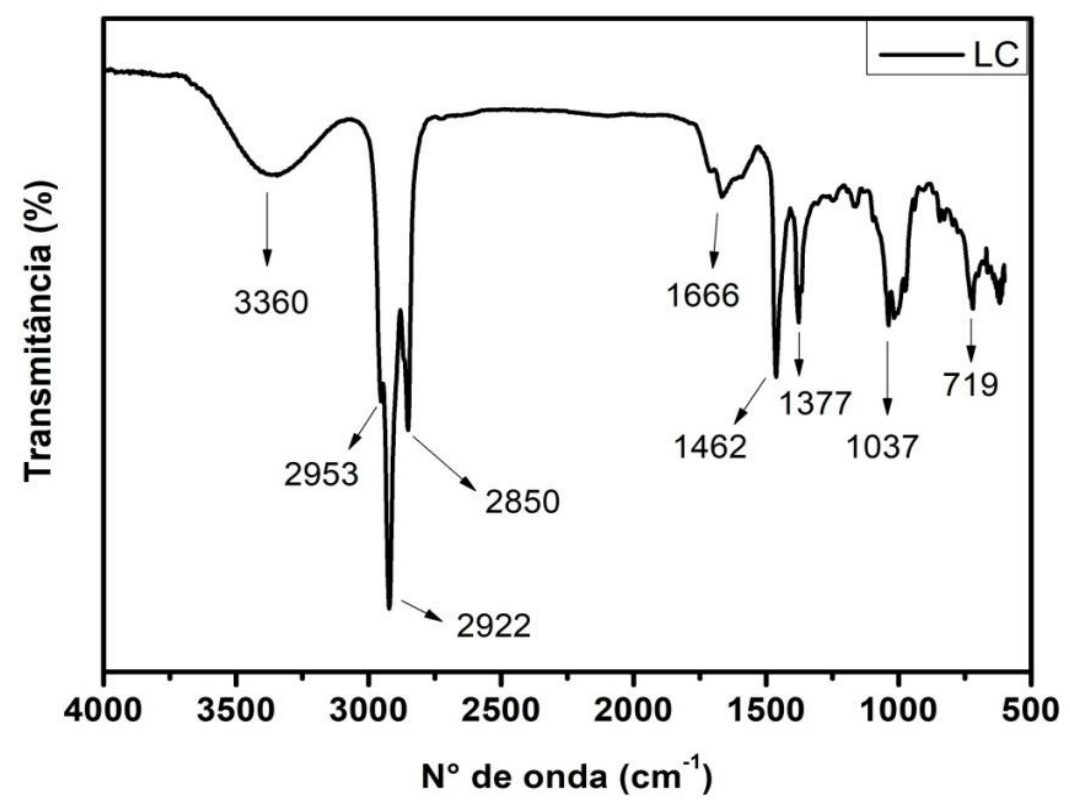

Figura 6. Espectro de infravermelho dos carotenoide totais - CCT, em pastilhas de KBr na região de 400 a $4.000 \mathrm{~cm}^{-1}$.

Ao se comparar o espectro de infravermelho da fração de carotenoides "C3" com o espectro da mistura de carotenoides totais, CCT (Figura 7), os espectros são bastante similares, apresentando banda de absorção característica para carbonila $(v C=0) \mathrm{em}$ $1.714 \mathrm{~cm}^{-1}$, para deformação de ligação de carbonos sp ${ }^{2}(\mathrm{~V} C=\mathrm{C})$ em $1.651 \mathrm{~cm}^{-1}, 1.462 \mathrm{~cm}^{-1} \mathrm{e}$ $1.369 \mathrm{~cm}^{-1}$ são também indicativos das vibrações de deformação angular de $v \mathrm{C}$-Hsp ${ }^{3} \mathrm{e}$ mais duas bandas evidenciadas ao redor de 1.037 e $1.095 \mathrm{~cm}^{-1}$ características para função tipo álcool e a banda ao redor de $732 \mathrm{~cm}^{-1}$ é característico da vibração $v \mathrm{C}_{\mathrm{sp} 2}-\mathrm{H}$ fora do plano.

Na Figura 8 podemos observar que a fração de carotenoide "C4" também apresentou um espectros padrão de carotenoides, ficando evidente a banda larga de absorção de hidroxila $(\mathrm{vOH})$ em $3.371 \mathrm{~cm}^{-1}$. Também apresenta bandas de vibração entre 3.000-2.852 $\mathrm{cm}^{-1}$ para $v \mathrm{C}_{\mathrm{sp} 2}-\mathrm{H}$ e $v \mathrm{C}_{\mathrm{sp} 3}-\mathrm{H}$. Em $1.720 \mathrm{~cm}^{-1}$ aparecem as bandas de absorção das carbonilas $(v \mathrm{C}=0)$ e em $1.648 \mathrm{~cm}^{-1}$ indica a presença de insaturação $(v \mathrm{C}=\mathrm{C})$. As bandas de absorção em $1.462 \mathrm{~cm}^{-1}$ e $1.377 \mathrm{~cm}^{-1}$ são também indicam as vibrações de deformação angular de $\mathrm{C}_{\mathrm{sp} 3}-\mathrm{H}$. A banda de absorção em $734 \mathrm{~cm}^{-1}$ é típico para deformação harmônica de ligação $\mathrm{C}_{\mathrm{sp} 2}-\mathrm{H}$ fora do plano.

Os resultados obtidos neste estudo foram semelhantes aos relatados por Medeiros (2018), ao analisar extrato bruto de melão rico em carotenoides. 


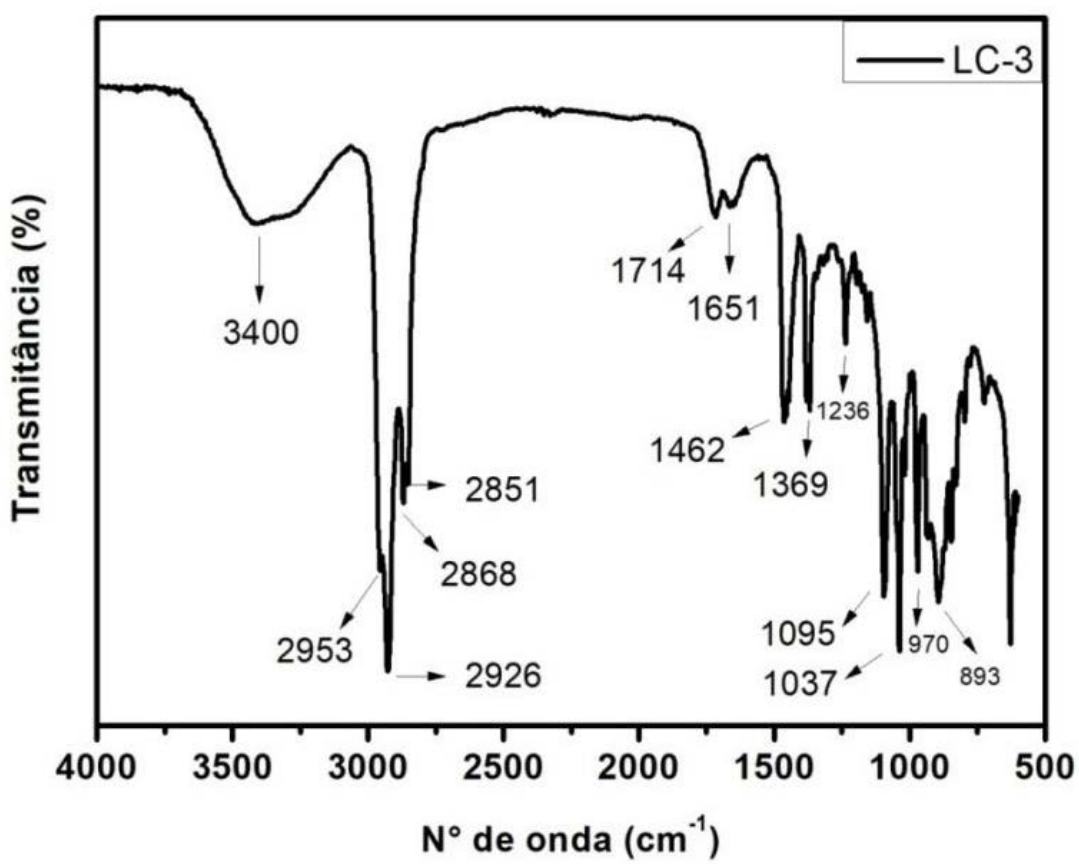

Figura 7. Espectro de infravermelho da fração de carotenoide C 3, em pastilhas de KBr na região de 400 a $4.000 \mathrm{~cm}^{-1}$.

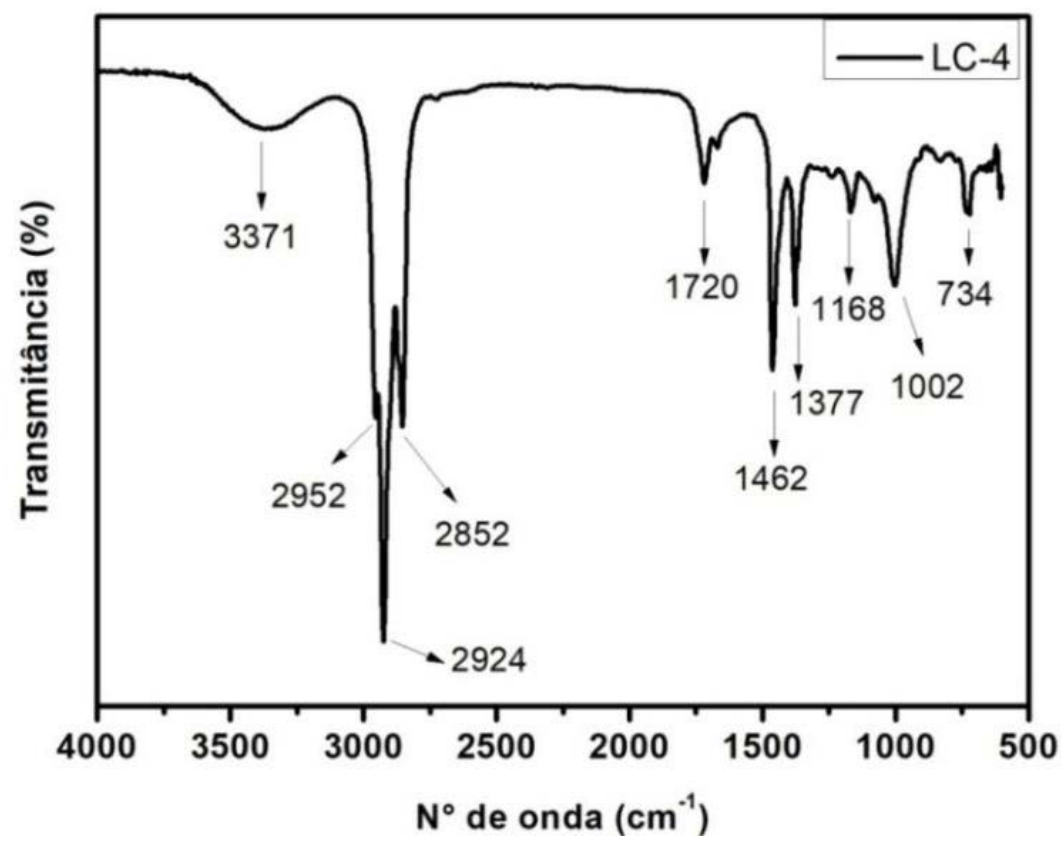

Figura 8. Espectro de infravermelho da fração de carotenoide C4, em pastilhas de $\mathrm{KBr}$ na região de 400 a $4.000 \mathrm{~cm}^{-1}$

A fração de carotenoide "C5" (Figura 9) também apresentou um espectros padrão de carotenoides, ficando evidente a banda de absorção de hidroxilas $(\mathrm{vOH})$ em $3.337 \mathrm{~cm}^{-1}$. As bandas entre 2.953-2.852 $\mathrm{cm}^{-1}$ estão atribuídas para $v \mathrm{C}_{\mathrm{sp} 2}-\mathrm{H}$ e $v \mathrm{C}_{\mathrm{sp} 3}-\mathrm{H}$. A banda de absorção característica de carbonila aparecem em $1.708 \mathrm{~cm}^{-1}(v \mathrm{C}=0)$ e para carbono 
insaturado em $1.668 \mathrm{~cm}^{-1}(\mathrm{vC}=\mathrm{C})$ (Pinheiro et al., 2014). A banda que aparece em $1.462 \mathrm{~cm}^{-1}$ e $1.377 \mathrm{~cm}^{-1}$ é o indicativo da existência de grupo $\mathrm{CH}_{3}$, ou seja deformação angular de ligação $v \mathrm{C}_{\mathrm{sp} 3}-\mathrm{H}$. Também aparecem as bandas de absorções de $v \mathrm{C}_{\mathrm{sp} 2}-\mathrm{H}$ fora do plano em $1001 \mathrm{~cm}^{-1}$ e $732 \mathrm{~cm}^{-1}$

Todos os espectros de infravermelho, tanto de CCT e das demais frações, corroboram com os estudos realizados por Ortega-Cabello et al. (2016). Nos estudos de espectroscopia de infravermelho com misturas de carotenoides pré-purificadas de Rhodococcus sp. e Gordonia sp., caracterizou as bandas de absorções correspondentes aos grupos hidroxila $v-\mathrm{OH}\left(3.400-3.362 \mathrm{~cm}^{-1}\right)$, vibrações das ligações $v \mathrm{C}_{\mathrm{sp} 2}-\mathrm{H} \quad \mathrm{e}_{\mathrm{sp} 3}-\mathrm{H}$ (2.922-2.852 $\left.\mathrm{cm}^{-1}\right)$ e absorção para grupo carbonila $v C=0\left(1.731\right.$ e $\left.1.714 \mathrm{~cm}^{-1}\right)$. Também nos estudos de Ortega-Cabello et al. (2016) as bandas das carbonilas (figura 10), também se apresentam como bandas de baixa intensidade.

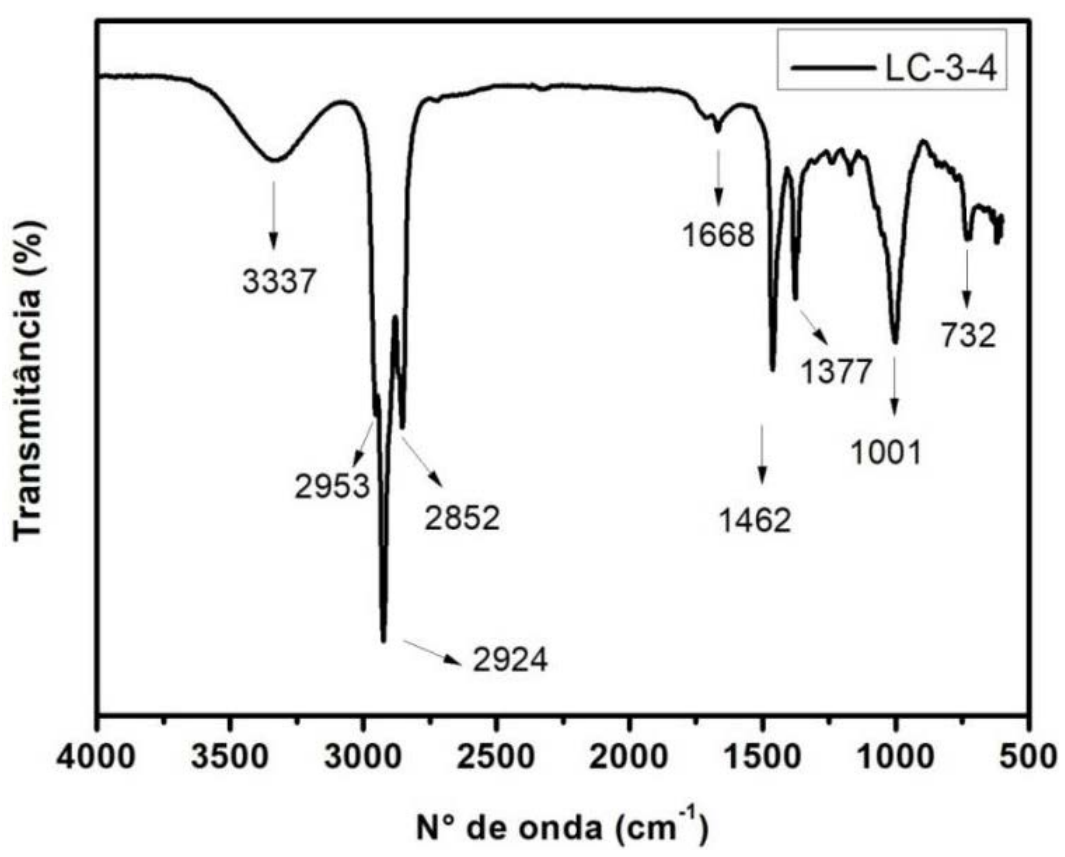

Figura 9. Espectro de infravermelho da fração de carotenoide $C 5$, em pastilha de $\mathrm{KBr}$, na região de 400 a $4.000 \mathrm{~cm}^{-1}$

Os estudos de FTIR não são totalmente elucidativos, apenas fornecem fortes evidências e asseguram que se trata de estruturas de compostos carotenoides, (Madeira, 2015). Entretanto, para a elucidação das moléculas total se faz necessários estudos mais aprofundados e complementares incluindo-se a Cromatografia, Ressonância Magnética Nuclear de ${ }^{1} \mathrm{H}$ e de ${ }^{13} \mathrm{C}$ uni e bidimensionais, homo e heteronuclear. 


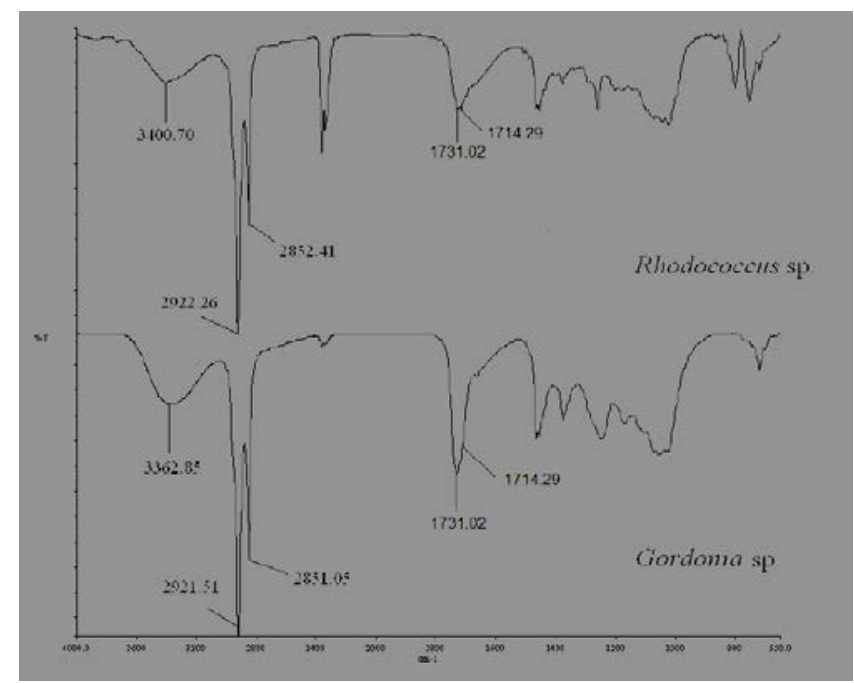

Figura 10. Espectro de infravermelho de Rhodococcus sp. e Gordonia sp. em pastilhas de $\mathrm{KBr}$ na região de 400 a $4.000 \mathrm{~cm}^{-1}$. Fonte: Ortega-Cabello et al. (2016).

\section{Análises termogravimétricas das frações saponificáveis e insaponificáveis da} microalga Scenedesmus quadricauda

As curvas de perda de massa das amostras das frações saponificáveis e insaponificáveis obtidas pelo processo de saponificação direta da biomassa da microalga Scenedesmus quadricauda, apresentaram eventos térmicos diferenciados.

A fração saponificável (Figura 11) apresenta duas etapas de perda de massa nos intervalos de $184{ }^{\circ} \mathrm{C}$ a $255{ }^{\circ} \mathrm{C}(37,2 \%)$ e $363{ }^{\circ} \mathrm{C}$ a $439{ }^{\circ} \mathrm{C}(60,3 \%)$. $\mathrm{O}$ primeiro evento térmico, corresponde a capacidade de conversão, indicando que esta se deu em torno de $97,5 \%$ após o processo de esterificação. O Segundo evento, apresentado no intervalo de $363{ }^{\circ} \mathrm{C}-439^{\circ} \mathrm{C}$, é característico de decomposição de lipídios, principalmente triglicerídeos (Rizzo et al., 2013) sendo pronunciado nesta amostra (maior que 60\%) indicando que houve eficiência em sua extração. Os dados obtidos corroboram com os relatados por Gomes (2013), quando da decomposição de lipídios.

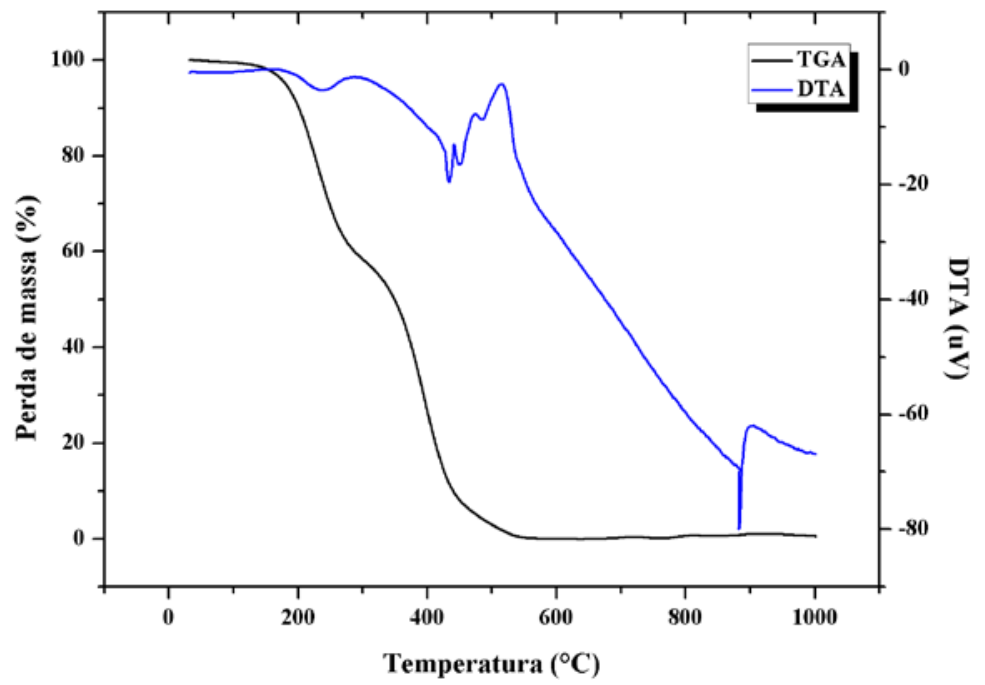

Figura 11. Curva TG/DTA da fração saponificável da biomassa da microalga Scenedesmus quadricauda. 
A curva TG insaponificável (Figura 12) apresenta três etapas de perda de massa (eventos térmicos) nos intervalos de $65^{\circ} \mathrm{C}$ a $103^{\circ} \mathrm{C}(5,2 \%), 191{ }^{\circ} \mathrm{C}$ a $312{ }^{\circ} \mathrm{C}(83 \%)$ e $463^{\circ} \mathrm{C}$ a $508{ }^{\circ} \mathrm{C}(10,2 \%)$. A primeira etapa $\left(65^{\circ} \mathrm{C}\right.$ a $\left.103^{\circ} \mathrm{C}\right)$ corresponde a processos de desidratação, devido à presença da água na forma livre e/ou fracamente ligada a biomoléculas (Zou et al., 2010), caracterizando conversão da biomassa após a esterificação em torno de $98,4 \%$.

A segunda etapa (intervalo de $191^{\circ} \mathrm{C}$ a $312^{\circ} \mathrm{C}$ ) está relacionado a um processo de volatilização, incluindo despolimerização e descarboxilação, atribuído principalmente à decomposição térmica de carboidratos e proteínas (Rizzo et al., 2013), o qual se constitui como um dos principais eventos de perda de massa, especialmente porque estes dois componentes são encontrados em quantidades significantes na microalga em estudo, principalmente no tocante aos carboidratos.

Importante salientar que a presença de proteína na biomassa microalgal torna plausível a utilização do material residual para fins alimentícios.

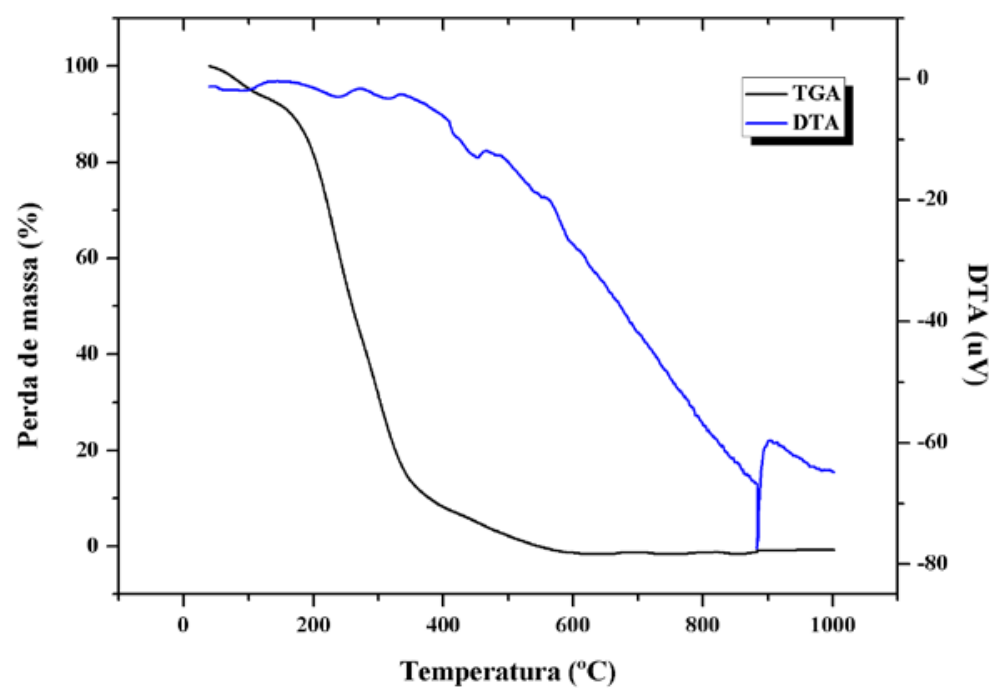

Figura 12. Curva TG/DTA da fração insaponificável da biomassa da microalga Scenedesmus quadricauda.

A calorimetria exploratória diferencial (DSC) possibilitou a medição direta de energia envolvida no comportamento térmico da amostra de biodiesel obtido da biomassa microalgal da Scenedesmus quadricauda (fração insaponificável) e do resíduo de biomassa (fração saponificável), por meio de uma relação linear entre a mudança de temperatura e o fluxo de calor. A compensação de potência no DSC é adotada por convenção termodinâmica em que eventos endotérmicos possuem variação positiva de entalpia $(\Delta \mathrm{H}>0)$ (Dermondes, 2016).

A Figura 13A ilustra a curva obtida com os materiais em estudo por meio do DSC, sendo o seu $\Delta \mathrm{H}$ de $640,4 \mathrm{KJ} / \mathrm{kg}$. 0 pico único observado representa a porção da curva de DTA. Nota-se que se trata de um pico exotérmico a aproximadamente $750 \mathrm{~K}$, referente a degradação de matéria orgânica presente no material, pois a temperatura da amostra tornou-se maior que a temperatura do material referência. 0 intervalo de temperatura de $-132,92^{\circ} \mathrm{C}$ a $508,49^{\circ} \mathrm{C}$ representou a saída e retorno à linha base da biomassa, sendo respectivamente, a temperatura inicial e final de fusão do material. 
A análise por Calorimetria Exploratória Diferencial (DSC) pode ser usada para avaliação do comportamento térmico, observando eventos de fusão, desnaturação e degradação da amostra (Gill et al., 2010). A temperatura pico é considerada a temperatura de desnaturação da amostra.

A curva DSC saponificável (Figura 13-B) apresenta quatro transições endotérmicas com pico a $382 \mathrm{~K}, 473 \mathrm{~K}, 548 \mathrm{~K}$ e $763 \mathrm{~K}$, e uma transição exotérmica com pico a aproximadamente $670 \mathrm{~K}$ atribuída a decomposição de carboidratos.
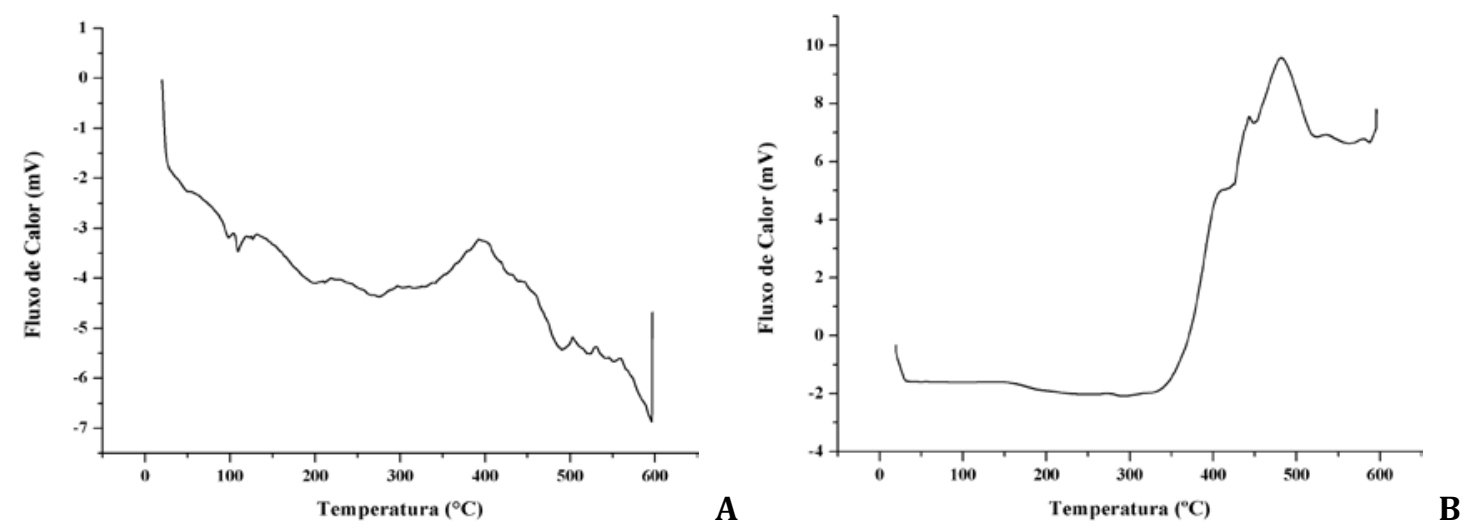

Figura 13. Curvas DSC da fração insaponificável e da fração saponificável da biomassa da microalga Scenedesmus quadricauda.

\section{Carotenoides como aditivo de biodiesel}

Estudos da estabilidade oxidativa da massa de carotenoide presente na fração insaponificável apresentou alta atividade antioxidante.

Objetivando testar a efetividade dos antioxidantes presentes na fração insaponificável, realizou-se a inserção de frações do produto rico em carotenoides como aditivo no biodiesel de algodão puro. 0 biodiesel em questão atende todas as especificações da ANP, portanto o produto ideal para o referido estudo. Nas análises realizadas com a metodologia Rancimat, é possível atestar-se a alta capacidade antioxidativa dos carotenoides. Utilizaram-se frações a 1,25\%, 2,5\% e 5\% respectivamente. Observou-se que na temperatura de $110{ }^{\circ} \mathrm{C}$ sem o aditivo o tempo de reação é de 4,57 h, ao ser aditivado com carotenoides a 1,25\% em peso, passou para 5,43 $\mathrm{h}$ $2,5 \%$ em peso, obteve-se $6,92 \mathrm{~h}$ e a $5 \%$ em peso o tempo de oxidação foi de $7,52 \mathrm{~h}$. (Tabela 2). Os resultados obtidos configuram a mistura de carotenoides obtidas na fração insaponificável da biomassa da $S$. quadricauda apresentam efetividade no tocante a otimização da capacidade de armazenamento do biodiesel quando aditivado com 0 produto obtido nesse estudo a $1,25 \%$. 
Tabela 2. Resultados de estabilidade oxidativa do biodiesel puro de algodão pelo método Rancimat a com adição de carotenoides presentes na fração insaponificável da microalga $S$. quadricauda a $110^{\circ} \mathrm{C}$.

\begin{tabular}{|l|c|}
\hline ID 2 & Tempo de indução \\
\hline $1,25 \%$ REP1 & $5,43 \mathrm{~h}$ \\
\hline $1,25 \%$ REP2 & $5,43 \mathrm{~h}$ \\
\hline $2,5 \%$ REP1 & $6,92 \mathrm{~h}$ \\
\hline $2,5 \%$ REP2 & $7,10 \mathrm{~h}$ \\
\hline $5,0 \%$ REP1 & $7,52 \mathrm{~h}$ \\
\hline $5,0 \%$ REP2 & $4,59 \mathrm{~h}$ \\
\hline Puro & $4,57 \mathrm{~h}$ \\
\hline
\end{tabular}

\section{Conclusões}

A microalga Scenedesmus quadricauda apresentou bom crescimento em cultivo com meio oriundo de biocompostagem, por demonstrar melhor desempenho quando comparado ao meio sintético.

A partir deste estudo, constatou-se que não há condições de prevermos regras de acumulação das proteínas lipídeos e carboidratos durante as fases de crescimento, tendo em vista que uma mesma espécie apresenta concentrações e tendências distintas ao variar o meio de cultivo, devido a variações nos teores de nitrogênio e fósforo, principalmente, fazendo-se necessário o acompanhamento da síntese desses compostos para assegurar o melhor momento para coleta da biomassa com o teor máximo do componente bioquímico desejado.

A técnica extrativa de saponificação direta seguida de transesterificação é eficiente no tocante a compostos bioativos, porém restritiva quando direcionada a produção de biodiesel.

A técnica de FTIR e CCD demonstrou eficiência no acompanhamento do acúmulo dos principais componentes bioquímicos da biomassa. Demonstrando que as respostas metabólicas relacionadas à síntese dos componentes bioquímicos foram favoráveis a produção de carotenoides, abrindo caminho para novas pesquisas a respeito, sugerindo que essas técnicas, por serem mais rápidas podem, de fato, serem utilizadas para o monitoramento de produtos de interesse em cultivos em massa para propósitos biotecnológicos de utilização das microalgas.

Apesar do estudo de infravermelho não ser uma técnica de espectroscopia elucidativa das estruturas químicas orgânicas, foi satisfatória para indicar que a fração apolar dos produtos, se refere a uma mistura de carotenoides.

Estudos de infravermelho indicam que a microalga Scenedesmus quadricauda é fonte de carotenoides com capacidade para o desenvolvimento de tecnologias de produtos e processos para a produção de aditivos antioxidantes.

0 produto extraído presente na fração insaturada apresentou características ótimas de antioxidação favorecendo seu uso como aditivo em biodiesel para melhora da estabilidade oxidativa.

\section{Agradecimentos}

O presente trabalho foi realizado com apoio da Coordenação de Aperfeiçoamento de Pessoal de Nível Superior - Brasil (CAPES) - Código de Financiamento 001. 


\section{Conflito de interesses}

Os autores declaram não haver conflito de interesses.

\section{Referências}

ABNT - Associação Brasileira de Normas Técnicas. ABNT NBR 10441:2014 - Produtos de petróleo - Líquidos transparentes e opacos-Determinação da viscosidade cinemática e cálculo da viscosidade dinâmica. Rio de Janeiro: ABNT, 2014.

Antonino, R. S. C. M. Q. Produção de quitosana a partir de exoesqueleto de camarão (Litopenaeus vannamei Boone) para aplicações biomédicas. Campina Grande: Universidade Federal de Campina Grande, 2016. (Dissertação de mestrado).

AOCS - American Oil Chemists' Society. Official methods and recommended practices of the American Oil Chemists' Society. 6. ed. Champaign: AOCS, 2009.

Araújo, V. B. S. Metabólitos de interesse à indústria alimentícia, produzidos por microalgas isoladas da Região Nordeste do Brasil. João Pessoa: Universidade Federal da Paraíba, 2018. (Tese de doutorado).

Babu, M.; Chakrabarti, R.; Sambasivarao, K. R. S. Enzymatic isolation of carotenoid-protein complex from shrimp head waste and its use as a source of carotenoids. LWT - Food Science and Technology, v. 41, p.227-235, 2008. https://doi.org/10.1016/ j.lwt.2007.03.006

Bermudez-Sierra, J. J. Extração de lipídeos da microalga Scenedesmus sp. com diferentes misturas de solventes orgânicos. Biotecnologia em el Sector Agropecuario y Agroindustrial, v. 16, n. 2, 2018. https://doi.org/10.18684/bsaa.16n2.1169

Brand-Willams, W.; Cuvelier, M. E.; Berset, C. Use of a free radical method to evaluate antioxidant activity. LWT - Food Science and Technology, v. 28, n. 1, p. 25-30, 1995. https://doi.org/10.1016/S0023-6438(95)80008-5

Brasil. Resolução ANP no 32, de 16 de outubro de 2007. Disponível em: $<$ http://legislacao.anp.gov.br/?path=legislacao-anp/resol-anp/2007/outubro\&item= ranp-32--2007>. Acesso em: 23 nov. 2019.

Carreres, B. M.; Jaeger, L.; Springer, J.; Barbosa, M. J.; Breuer, G.; van den End, E. J.; Kleinegris, D. M. M.; Schäffers, I.; Wolbert, E. J. H.; Zhang, H.; Lamers, P. P.; Draaisma, R. B.; Martins dos Santos, V. A. P.; Wijffels, V. A. P.; Eggink, G.; Schaap, P. J.; Martens, D. E. Draft genome sequence of the oleaginous green alga Tetradesmus obliquus UTEX 393. Genome Announcements, v. 5, n. 3, e01449-16, 2017. https://doi.org/10.1128/genomeA.0144916

Cavalcanti, A. K. O. Nanoencapsulação de carotenoides de melão Cantaloupe (Cucumis melo L. reticulatus Naud.): caracterização de partículas, avaliação da solubilidade em água e estabilidade de cor em iogurte. Natal: Universidade Federal do Rio Grande do Norte, 2018. (Dissertação de mestrado).

Cheng, Y.-T.; Yang, C.-F. Using strains of Rhodotorula mucilaginosa to produce carotenoids using food wastes. Journal of the Taiwan Institute of Chemical Engineers, v. 61, p. 270-275, 2016. https://doi.org/10.1016/j.jtice.2015.12.027

Chitralekha, B.; Priya, V. V.; Gayathri, R. Preliminary phytochemical analysis and total phenolic content of Solanum giganteum leaves and fruit extract. Drug Invention Today, v. 10, n. 9, p. 1712-1715, 2018. 
Choochote, W.; Suklampoo L.; Ochaikul, D. Evaluation of antioxidant capcities of green microalgae. Journal of Applied Phycology, v. 26, n. 1, p. 43-48, 2014. https://doi.org/ 10.1007/s10811-013-0084-6

Costa, N. M. B.; Rosa, C. O. B. Alimentos funcionais: componentes bioativos e efeitos. Rio de Janeiro: Rubio, 2010.

Dermondes, R. Análise térmica DSC. Scribd, 2016.

Gill, M.; Smith, P.; M. Wilkinson, J. Mitigating climate change: The role of domestic livestock. Animal: An International Journal of Animal Bioscience, v. 4, p. 323-333, 2010. https://doi.org/10.1017/S1751731109004662

Gomes, F. G. Extração e análise da fração lipídica da microalga Monoraphidium sp., síntese e caracterização do seu biodiesel. Natal: Universidade Federal do Rio Grande do Norte, 2013. (Dissertação de mestrado).

Gross, F. Notes on the culture of some marine organisms. Journal of Marine Biology, v. 21, n. 2, p. 753-768, 1937.

Hartman, L.; Lago, R. C. A. Rapid preparation of fatty acids methyl esters. Laboratory Practice, v. 22, p. 475-476, 1973.

Harun, R.; Singh, M.; Forde, G. M.; Danquah, M. K. Bioprocess engineering of microalgae to produce a variety of consumer products. Renewable and Sustainable Energy Reviews, v. 14, n. 3, p. 1037-1047, 2010. https://doi.org/10.1016/j.rser.2009.11.004

Ibañez E.; Cifuentes A. Benefits of using algae as natural sources of functional ingredients. Journal of the Science of Food and Agriculture, v. 93, n. 4, p.703-709, 2013. https://doi.org/10.1002/jsfa.6023

Kanzy, M.; Nasr, N. F.; El-Shazly, H. A. M.; Barakat, O. S. Optimization of carotenoids production by yeast strains of Rhodotorula using salted cheese whey. International Journal of Current Microbiology and Applied Sciences, v. 4, p. 456-469, 2015.

Kolympiris, C.; Kalaitzandonakes, N.; Miller, D. Public funds and local biotechnology firm creation. Research Policy, v. 43, n. 1, p. 121-137, 2014. https://doi.org/10.1016/ j.respol.2013.07.012

Madeira, A. M. Extração e quantificação de carotenoides provenientes de diferentes cultivares de Capsicum annuum com interesse para a indústria farmacêutica. Porto: Universidado do Porto, 2015. (Dissertação de mestrado).

Markou, G.; Angelidaki, I.; Georgakakis, D. Microalgae carbohydrates: An overview of the factors influencing carbohydrates production, and of main bioconversion technologies for production of biofuels. Applied Microbiology and Biotechnology, v. 96, p. 631-645, 2012. https://doi.org/10.1007/s00253-012-4398-0

Markou, G.; Nerantzis, E. Microalgae for high-value compounds and biofuels production: A review with focus on cultivation under stress conditions. Biotechnology Advances, v. 31, n. 8, p. 1532-1542, 2013. https://doi.org/10.1016/j.biotechadv.2013.07.011

Nogara, G. P.; Fernandes, A. S.; Muller, B.; E., Jacob-Lopes; Zepka, L. Q. Identificação de carotenoides da biomassa de Phormidium autumnale obtidos através de extração assistida por ultrassom e avaliação do potencial de produção destes compostos, à partir de cultivo fototrófico. Anais do XI Congresso Brasileiro de Engenharia Química, UNICAMP, Campinas, 2015. https://doi.org/10.5151/chemeng-cobeqic2015-439-34059-261745 
Nomura, R. B. G.; Oliveira, G. G.; Bertão, A. M. S.; Andrade, D. S. Composição química e atividade biológica da microalga Chlorella sorokiniana (IPRM7175). Anais do V Simpósio de Bioquímica e Biotecnologia, Londrina, 2015. https://doi.org/10.5151/biochemvsimbbtec-21972

Ortega-Cabello, L. O.; Méndez, H. I. P.; Alvarez, N. M.; Manjarrez, L. A. M.; Hernández, J. C.; Canod, E. T. Q.; Luna, A. L. Characterization and antioxidant activity of carotenoid mixtures present in Rhodococcus sp. and Gordonia sp. Journal of Chemical and Pharmaceutical Research, v. 8, n. 5, p. 879-888, 2016.

Patil, P. D.; Dandamudi, K. P. R.; Wang, J.; Deng, Q.; Deng, S. Extraction of bio-oils from algae with supercritical carbon dioxide and co-solvents. Journal of Supercritical Fluids, v. 135, p. 60-68, 2018. https://doi.org/10.1016/j.supflu.2017.12.019

Pinheiro, C. P.; Insognia, A.; Strieder, M. M.; Pohndorf, R. S.; Pinto, L. A. A. Extração de lipídios de microalga: avaliação da qualidade utilizando espectroscopia de infravermelho FT-IR. Anais do X Congresso Brasileiro de Engenharia Química Iniciação Científica, UFRRJ, Seropédica, 2014. https://doi.org/10.5151/chemeng-cobec-ic-03-ts-084

Rawat, I.; Kumar, R. R.; Mutanda, T.; Bux, F. Biodiesel from microalgae: A critical evaluation from laboratory to large scale production. Applied Energy, v. 103, p. 444-467, 2013. https://doi.org/10.1016/j.apenergy.2012.10.004

Rizzo, A. M.; Prussi, M.; Bettucci, L.; Libelli, I. M.; Chiaramonti, D. Characterization of microalgae Chlorella as a fuel and its thermogravimetric behavior. Applied Energy, v. 102, p. 24-31, 2013. https://doi.org/10.1016/j.apenergy.2012.08.039

Rohman, A.; Man, Y. B. C. Fourier Transform Infrared (FTIR) spectroscopy for analysis of extra virgin olive oil adulterated with palm oil. Food Research International, v. 43, n. 3, p. 886-892, 2010. https://doi.org/10.1016/j.foodres.2009.12.006

Rufino, M. S. M.; Alves, R. E.; Brito, E. S.; Morais, S. M.; Sampaio, C. G.; Pérez-Jiménez, J.; Saura-Calixto, F. D. Metodologia científica: determinação da atividade antioxidante total em frutas pelo método de redução do ferro (FRAP). Comunicado Técnico, n. 125, p. 1-4, 2006.

Rufino, M. S. M.; Alves, R. E.; Brito, E. S.; Morais, S. M.; Sampaio, C. G.; Pérez-Jiménez, J.; Saura-Calixto, F. D. Metodologia científica: determinação da atividade antioxidante total em frutas pela captura do radical livre DPPH. Comunicado Técnico, n. 127, p. 1-4, 2007.

Silverstein, R. M.; Webster, F. X. Spectrometric identification of organic compounds. 7. ed. Rio de Janeiro: LTC, 2007.

Sulochana, S. B.; Arumugam, M. Influence of abscisic acid on growth, biomass and lipid yield of Scenedesmus quadricauda under nitrogen starved condition. Bioresource Technology, v. 213, p. 198-203, 2016. https://doi.org/10.1016/j.biortech.2016.02.078

Viegas, C. V.; Hachemi, I.; Mäki-Arvela, P.; Smeds, A.; Aho, A.; Freitas, S. P.; Gorgônio, C. M. S.; Carbonetti, G.; Peurla, M.; Paranko, J.; Kumar, N.; Aranda, D. A. G.; Murzin, D. Yu. Algal products beyond lipids: Comprehensive characterization of different products in direct saponification of green alga Chlorella sp. Algal Research, v. 11, p. 156-164, 2015. https://doi.org/10.1016/j.algal.2015.06.014

Vieler, A.; Wu, G.; Tsai, C.-H.; Bullard, B.; Cornish, A. J.; Harvey, C.; Reca, I.-B.; Thornburg, C.; Achawanantakun, R.; Buehl, C. J.; Campbell, M. S.; Cavalier, D.; Childs, K. L.; Clark, T. J.; Deshpande, R.; Erickson, E.; Ferguson, A. A.; Handee, W.; Kong, Q.; Li, X.; Liu, B.; Lundback, S.; Peng, C.; Roston, R. L.; Sanjaya; Simpson, J. P.; TerBush, A.; Warakanont,J.; Zäuner, S.; Farre, E. M.; Hegg, E. L.; Jiang, N.; Kuo, M.-H.; Lu, Y.; Niyogi, K. K.; Ohlrogge, J.; Osteryoung, 
K. W.; Shachar-Hill, Y.; Sears, B. B.; Sun, Y.; Takahashi, H.; Yandell, M.; Shiu, S.-H.; Benning, C. Genome, functional gene annotation, and nuclear transformation of the heterokont oleaginous alga Nannochloropsis oceanica CCMP1779. PLoS Genetics, v. 8, p.11, e1003064, 2012. https://doi.org/10.1371/journal.pgen.1003064

Zou, S. P.; Wu, Y.; Yang, M.; Lic, C.; Tong, J. Bio-oil production from sub- and supercritical water liquefaction of microalgae Dunaliella tertiolecta and related properties. Energy \& Environmental Science, v. 3, p. 1073-1078, 2010. https://doi.org/10.1039/C002550J 